\title{
Association between Shopping Items and the Demographics of Foreign Tourists in South Korea*
}

\author{
Dong-Bin Jeong \\ Professor, Department of Information Statistics, Gangneung-Wonju National University, Gangneung, \\ Korea. \\ E-mail: dj@gwnu.ac.kr
}

Received: June 28, 2019. Revised: September 11, 2019. Accepted: September 20, 2019.

\begin{abstract}
Purposes - In this research, we look over and investigate associations between shopping items and the demographics of foreign tourists in South Korea. The related seven variables are gender, age, occupations, country of residence, visit month, visit purpose and trip type. In addition, we can graph twenty-one shopping items in association with the demographics of foreign tourists by computing their dissimilarity or similarity on two dimension planes granting that the association exists between the underlying variables.

Research design and methodology - This research is performed by Ministry of Culture and Tourism in 2017 and investigated 13,200 foreign tourists from 20 countries. For analyzing the detailed relationships between shopping items and the demographics of foreign tourists, we take advantage of both independent test and correspondence analysis as key statistical techniques.

Results - The findings show that shopping items which foreign tourists purchase are closely associated with the three different demographics variables such as country of residence, tour type and visit purpose by monitoring significant $\mathrm{p}$-value of chi-squared statistic

Conclusions - This study suggests Ministry of Culture, Sports and Tourism must explore ways toward tourism infrastructure such as global marketing, municipality strategy for attracting foreign tourists, development of diverse shopping items and services and so on.
\end{abstract}

Key words: Chi-squared test, Correspondence analysis, Demographics

JEL Classification Code: C12, M10, M30, N75, Q12.

\footnotetext{
${ }^{*}$ This work was supported by the Research Institute of Natural Science of Gangneung-Wonju National University.
} 


\section{Introduction}

Tourism promotion agency, reportedly, the total of foreigners who visited South Korea was 1.53 million, which increased 31.1 percent in October 2018 from a year earlier mainly because of a base effect after visits by Chinese nationals plunged in 2017. The number of Chinese tourists soared up to 37.6 percent. Owing to a major K-pop festival opened in Busan, the number of visitors from Japan also skyrocketed 61.7 percent. In addition, the yearly number of Taiwanese tourists visiting South Korea surpassed the 1 million mark for the first time this week on the back of the popularity of Korean pop culture and low-cost carriers (Nov 22, 2018, Yonhap).

The following articles are closely related to shopping items purchased by foreign tourist and useful to understand the main ideas of this work. Jeong (2019) classify the 21 shopping products which foreign tourists buy in South Korea and examine the class of similarity between each products and express appearance of proximities among a number of shopping products based on attributes of purpose of visit in 2017.

Nakahara (2017) considered associations and distinction between foreign tourists and local residents as one of international problems and propose the clue for how to settle benefits of both side, to build up and to maintain a partnership for the mutual interest among the concerned. Park and Jeong (2010) compared Japanese to Chinese tourists in South Korea in terms of shopping satisfaction. Satisfaction for nine shopping traits such as price, quality, design, package and so on is taken into account. They show that shopping goods and services of Japanese tourists are greatly different from those of Chinese and expectations of Japanese tourists for all shopping satisfaction attributes are not satisfactory, whereas those of Chinese tourists are somewhat satisfactory for all chosen nine attributes. In addition, both Japanese and Chines tourists are satisfied with shopping in South Korea, according to the survey.

In this work, we investigate meaningful associations among 21 attributes of shopping items and seven demographics by independence test, compute the measurable degree and denote their distances on two-dimensional plane. The related seven variables are gender, age, occupations, country of residence, visit month, visit purpose and trip type. In addition, we can graph twenty-one shopping items in association with the demographics of foreign tourists by computing their dissimilarity or similarity on two dimension planes granting that the association exists between the underlying variables.

Data collection and two statistical analyses will be briefly mentioned in section 2. Associations between seven demographics and shopping items will be denoted as p-value of chi-squared statistic, combination of these attributes will be graphed as a bi-plot in section 3 and the discussion will be treated on these statistical analyses. Finally, conclusion remarks and imitations of this research will be referred in section 4 .

\section{Data Collection and Statistical Methods}

Ministry of Culture, Sports and Tourism enforced a face-to-face survey of 16,000 foreign tourists who were from 20 countries in 2017, over 15 years old and stayed one day to a year in South Korea. Note that captains, crewpersons and soldiers among them excluded.

The demographics of foreign tourists under consideration are gender, age, occupations, country of residence, visit month, visit purpose and trip type.

The considered 21 shopping items are the following: cosmetics \& perfume, clothing, groceries, shoes, leather, ginseng \& Asian herb, kimchi, jewel \& accessory, folkcraft \& lacquer, electric appliances, liquor, watch, tabacco, books \& stationery, album \& DVD, star related products, doll \& toy, silk \& textile, china \& porcelain, ETS, and nothing.

The purpose of this survey is to utilize useful information of building up tourism policy in order to both enhance attraction of and better arrangement to receive foreign tourists, by routinely investigating, comparing and analyzing preference of travel and structural shift.

For finding details of associations between two qualitative variables, two crucial statistical techniques are exploited - chi-squared test and correspondence analysis. Correspondence analysis is a method for visually showing a two-way table by computing coordinates denoting its rows and columns. These coordinates are similar to factors in a principal components analysis, except that they split the chi-square statistic exploited in testing independence, not the total variance.

Once detecting significant relationship between two variables, we can change this relationship to a graphical 
display, in which we describe all rows and columns as a dot. We can figure out visually the degree of associations by observing the distance among attributes of the corresponding variables (Greenacre, 1984; Hoffman \& Franke, 1986; Clausen, 1988; Benzercri, 1992; Greenacre, 2007; Hair et al., 2007; Brigitte, 2009; Steven, 2009; Doey \& Kurta, 2011; Yang, 2013).

\section{Research Results}

\subsection{Association between COUNTRY OF RESIDENCE and shopping items}

The three shopping items which foreign tourists purchase - 'cosmetics \& perfume', 'clothing' and 'groceries' are key ones for all countries of residence (see Figure 1). In particular, 'cosmetics \& perfume' is the most frequent, whereas 'china \& porcelain' is the least frequent for all shopping items and countries of residence.

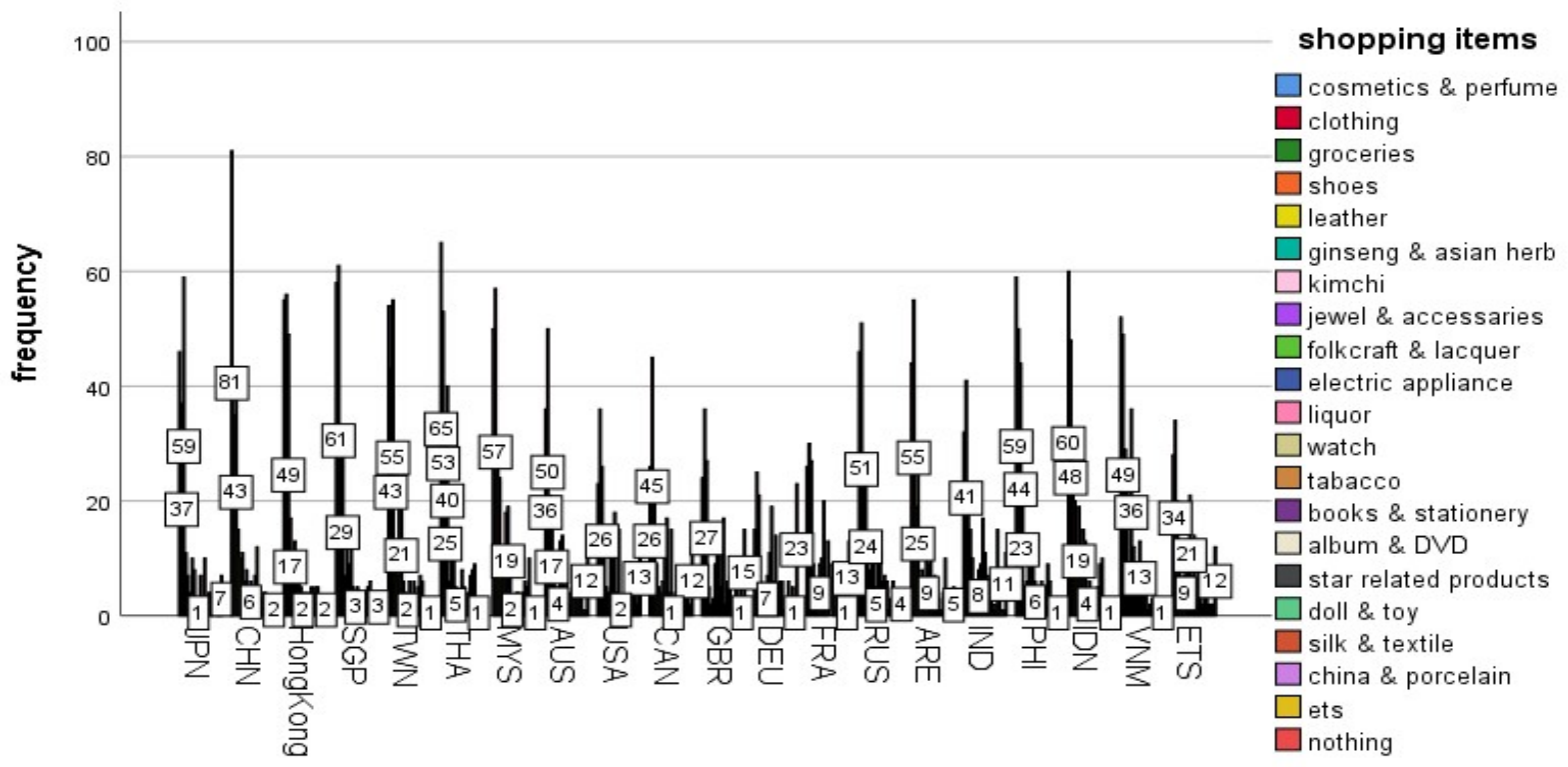

Figure 1: Bar chart on Country of Residence

We can find that there exists a highly significant association between countries of residence and shopping items (p-value $<.001$ ). The first, the second and the third explain $10.8 \%, 3.1 \%$ and $2.1 \%$, respectively of the total $21.1 \%$ of variance explained in the model (see Table 1).

Table 1: Summary on country of residence

\begin{tabular}{|c|c|c|c|c|c|c|c|c|}
\hline \multirow{2}{*}{ Dimension } & Singular & & & & \multicolumn{2}{|c|}{ Proportion of Inertia } & \multicolumn{2}{c|}{ Confidence Singular Value } \\
\cline { 5 - 8 } & Value & Inertia & Chi Square & P value. & Accounted & Cumulated & $\begin{array}{c}\text { Standard } \\
\text { Deviation }\end{array}$ & Correlation \\
\cline { 5 - 8 } & & & & & .514 & .514 & .014 & .012 \\
2 & .329 & .108 & & & .147 & .661 & .015 & \\
3 & .176 & .031 & & & .100 & .760 & & \\
4 & .145 & .021 & & & .081 & .842 & & \\
5 & .084 & .017 & & & .034 & .875 & \\
6 & .082 & .007 & & & .032 & .907 & & \\
7 & .072 & .007 & & & .025 & .932 & & \\
8 & .065 & .005 & & & .020 & .952 & & \\
9 & .057 & .003 & & & .016 & .967 & & \\
10 & .045 & .002 & & & .009 & .977 & & \\
\hline
\end{tabular}




\begin{tabular}{|l|l|l|l|l|l|l|l|}
\hline 11 & .042 & .002 & & & .008 & .985 & \\
12 & .030 & .001 & & & .004 & .990 \\
13 & .027 & .001 & & & .004 & .993 \\
14 & .025 & .000 & & & .003 & .996 \\
15 & .015 & .000 & & & .002 & .998 \\
16 & .012 & .000 & & & .001 & .999 & \\
17 & .012 & .000 & & & .001 & 1.000 & \\
18 & .006 & .000 & & & .000 & 1.000 & \\
19 & .001 & .000 & & & .000 & 1.000 & \\
Total & & .211 & .999 .119 & $<.001$ & 1.000 & 1.000 & \\
\hline
\end{tabular}

The first, the second and the third dimension account for $51.4 \%, 14.7 \%$ and $10 \%$ respectively of the total $21.1 \%$ of variance explained in the model (see Table 1).

A graph plot on Figure 2 indicates visual relationships of all attributes of both countries of residence and shopping items by foreign tourists by calculating the distance between each attribute. We can find that 'Japan', 'India', 'Deutsch', 'USA', “Australia', 'Indonesia', 'Philippines', and 'Malaysia' are deeply related to 'groceries', 'silk \& textile', 'china \& porcelain', 'books \& stationery', 'jewel \& accessary', 'leather', 'star related product', and 'clothing', respectively from $<$ Figure $2>$.

In addition, 'kimchi' among shopping items is marginally connected with both 'China' and 'Philippines', while 'ginseng \& Asian herb' is with both 'Thailand' and 'Vietnam'.

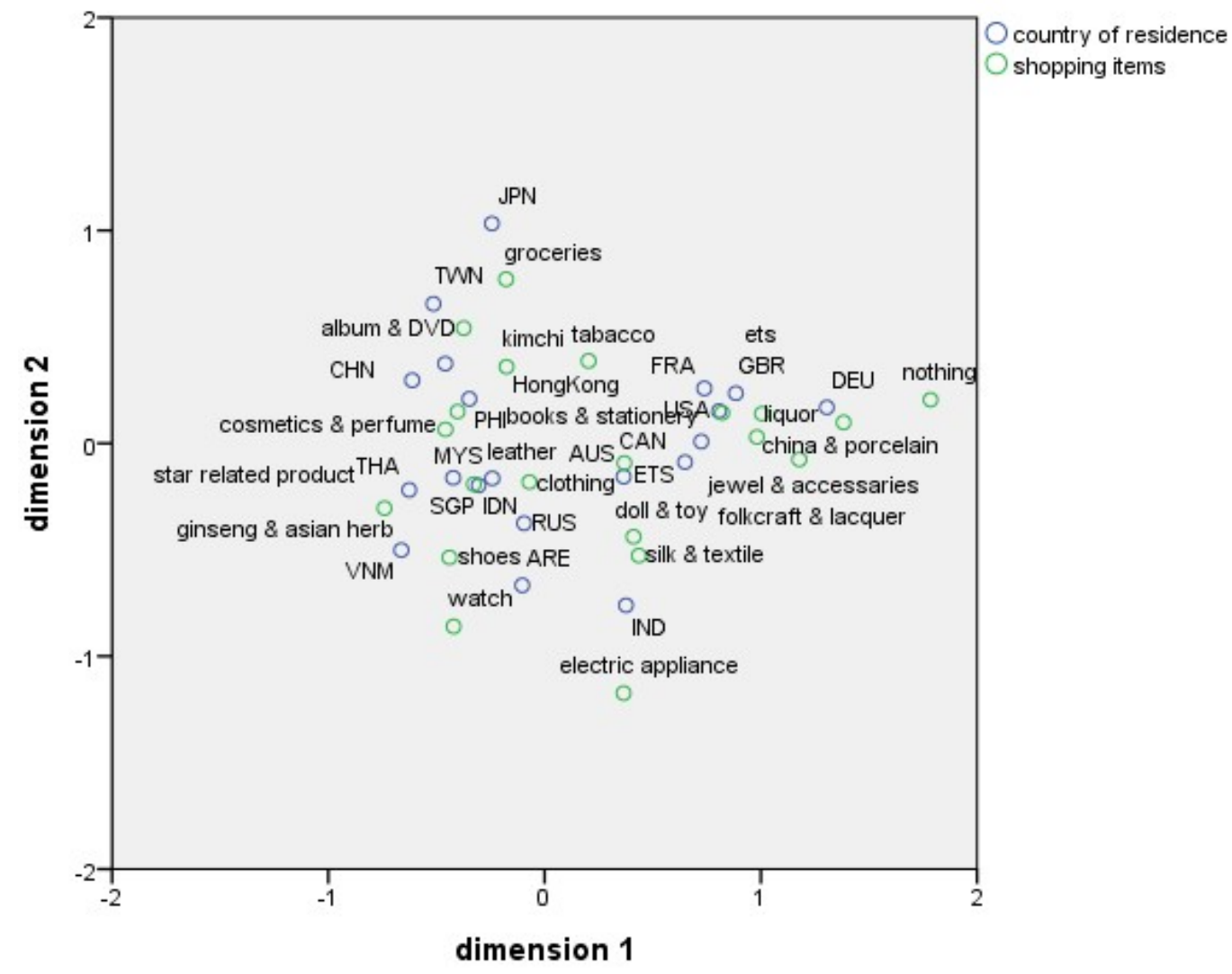

Figure 2: Row and column points with symmetric normalization 


\subsection{Association between TOUR TYPE and shopping items}

As we can see in section 3.1, we can find that 'cosmetics \& perfume', 'clothing' and 'groceries' are the main shopping items for all three kinds of tour types. In addition, 'cosmetics \& perfume' for air-tel tour is the most frequent $(66,26.8 \%$ of tour type, $36.3 \%$ of shopping items, $8.7 \%$ of total), whereas 'silk \& textile', 'china \& porcelain' are relatively less frequent for all shopping items and tour type (see Figure 3).

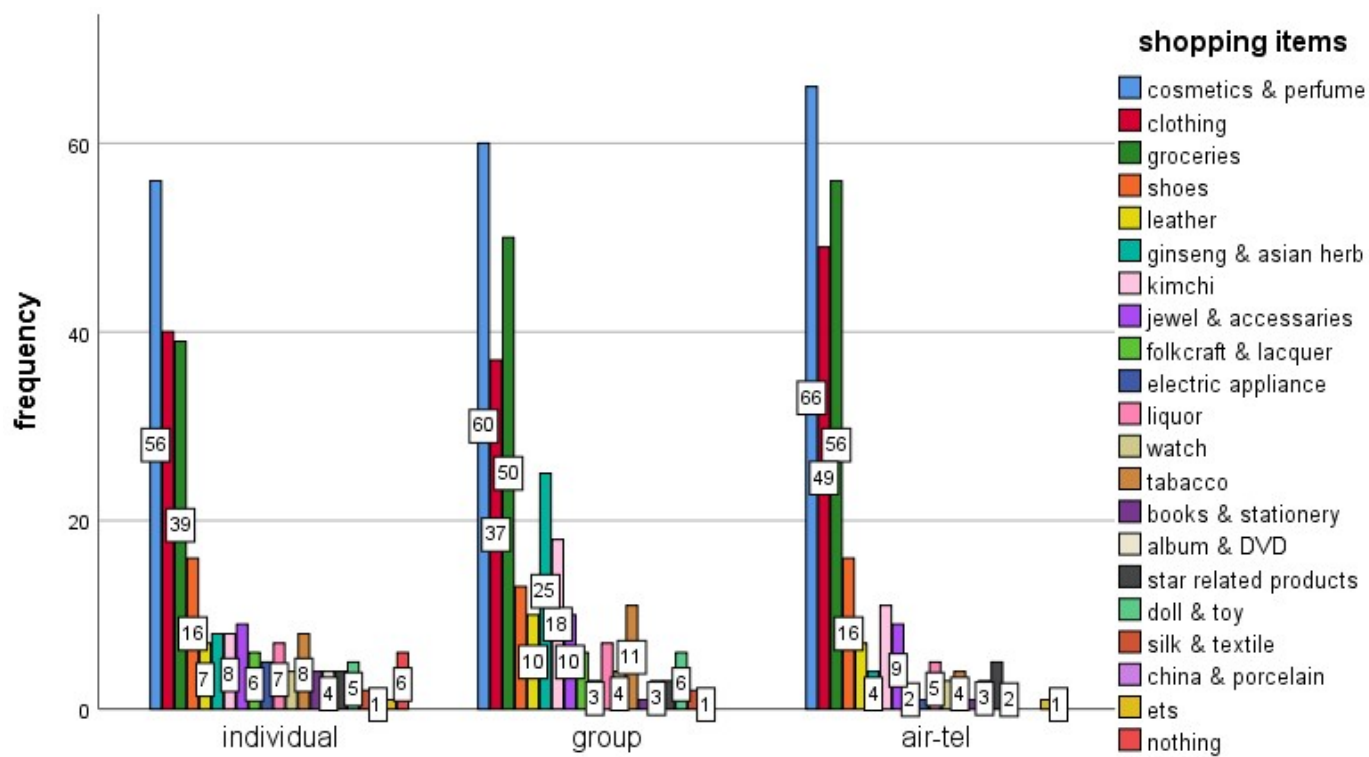

Figure 3: Bar chart on TOUR TYPE

The chi-squared test on Table 2 below shows that an intimate relationship between tour type and shopping items (p-value $=.008$ ), and the first and the second dimension account for $61.0 \%$, and 39.05 , respectively of the total $7.0 \%$ of variance explained in the model.

Table 2: Summary on tour type

\begin{tabular}{|c|c|c|c|c|c|c|c|c|}
\hline \multirow{3}{*}{ Dimension } & \multirow{3}{*}{$\begin{array}{l}\text { Singular } \\
\text { Value }\end{array}$} & \multirow{3}{*}{ Inertia } & \multirow{3}{*}{$\begin{array}{c}\text { Chi } \\
\text { Square }\end{array}$} & \multirow{3}{*}{ P value. } & \multicolumn{2}{|c|}{ Proportion of Inertia } & \multicolumn{2}{|c|}{ Confidence Singular Value } \\
\hline & & & & & \multirow{2}{*}{ Accounted } & \multirow{2}{*}{ Cumulated } & \multirow{2}{*}{$\begin{array}{c}\text { Standard } \\
\text { Deviation }\end{array}$} & Correlation \\
\hline & & & & & & & & 2 \\
\hline 1 & .207 & .043 & & & .610 & 610 & .033 & -.036 \\
\hline 2 & .165 & .027 & & & .390 & 1.000 & .037 & \\
\hline Total & & .070 & 52.597 & .008 & 1.000 & 1000 & & \\
\hline
\end{tabular}

We can find that 'group tour' among tour types is marginally connected with both 'kimchi' and 'leather' among shopping items, while 'individual tour' is with both 'liquor' and 'album \& DVD' from Figure 4. Also, 'air-tel tour' is marginally linked to both 'groceries' and 'clothing'. 


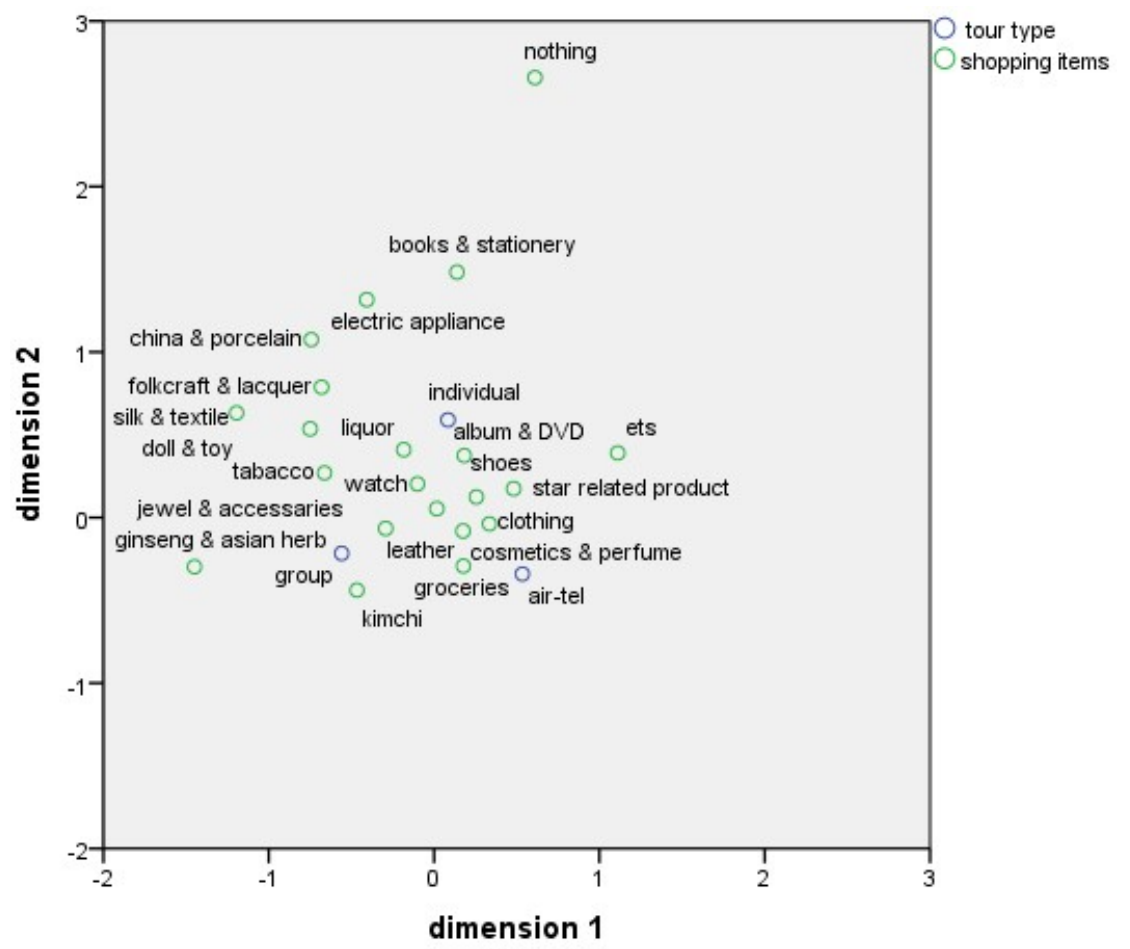

Figure 4: Row and column points with symmetric normalization

\subsection{Association between VISIT PURPOSE and shopping items}

From Figure 5, we can find that 'cosmetics \& perfume', 'clothing' and 'groceries', along with 'shoes', are the key shopping items for all attributes of visit purpose. Particularly, 'cosmetics \& perfume' for shopping is the most frequent $(80,29.3 \%$ of tour type, $21.1 \%$ of shopping items, $4.3 \%$ of total), whereas 'silk \& textile', 'china \& porcelain' is the least frequent for all shopping items and visit purpose as seen in section 3.2 (see Figure 5).

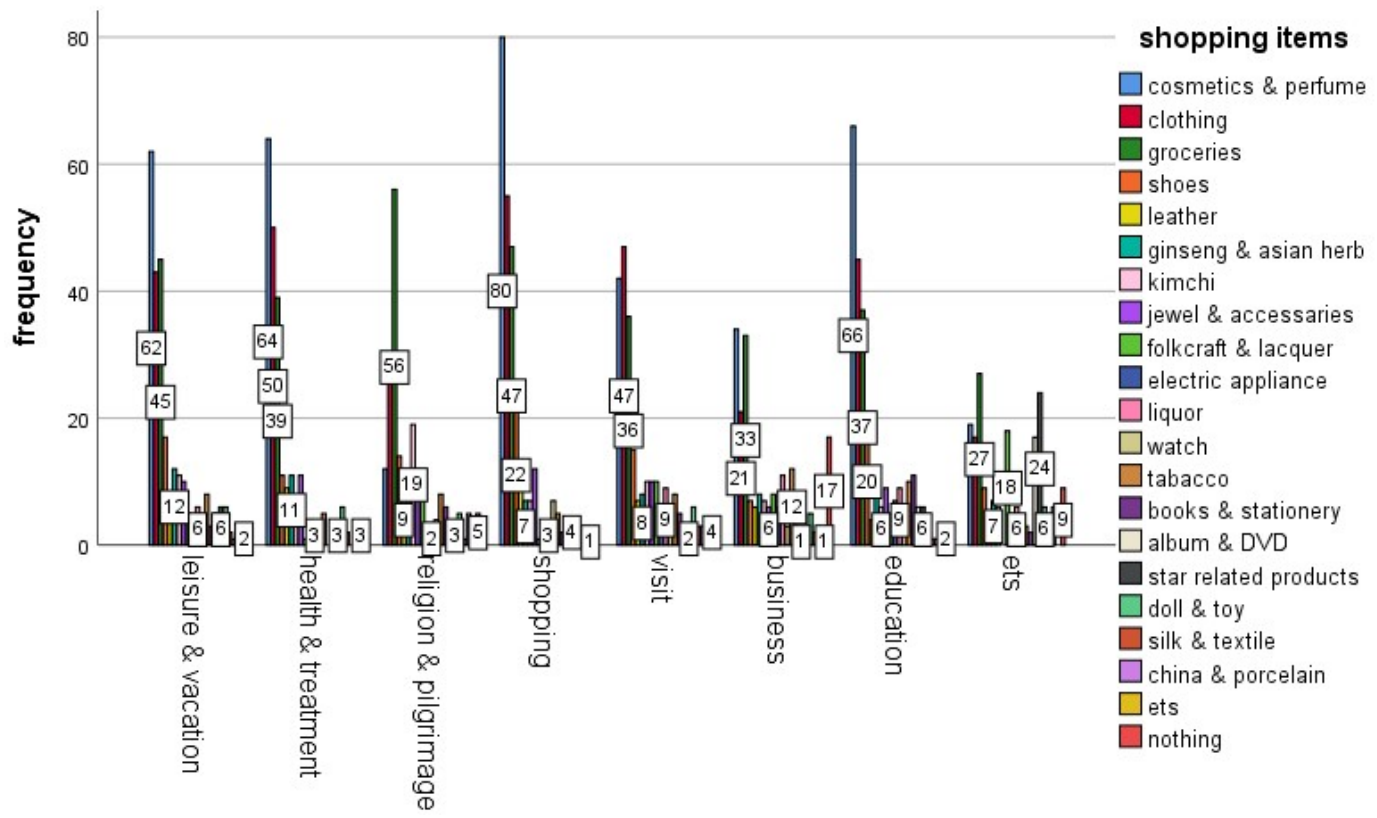

Figure 5: Bar chart on VISIT PURPOSE 
The chi-squared test from Table 3 below indicates the highly significant association between visit purpose and shopping items ( $\mathrm{p}$-value <.001). In particular, dimension 1, 2, and 3 accounts for $54.3 \%, 22.4 \%$ and 12.9 , respectively, and the first 3 dimensions explain $89.7 \%$ of total inertia.

Table 3: Summary on occupations

\begin{tabular}{|c|c|c|c|c|c|c|c|c|}
\hline \multirow{3}{*}{ Dimension } & \multirow{3}{*}{$\begin{array}{l}\text { Singular } \\
\text { Value }\end{array}$} & \multirow{3}{*}{ Inertia } & \multirow{3}{*}{$\begin{array}{c}\text { Chi } \\
\text { Square }\end{array}$} & \multirow{3}{*}{$\mathrm{P}$ value. } & \multicolumn{2}{|c|}{ Proportion of Inertia } & \multicolumn{2}{|c|}{ Confidence Singular Value } \\
\hline & & & & & \multirow{2}{*}{ Accounted } & \multirow{2}{*}{ Cumulated } & \multirow{2}{*}{$\begin{array}{l}\text { Standard } \\
\text { Deviation }\end{array}$} & Correlation \\
\hline & & & & & & & & 2 \\
\hline 1 & .373 & .139 & & & .543 & .543 & .030 & .084 \\
\hline 2 & .240 & .057 & & & .224 & .768 & .022 & \\
\hline 3 & .181 & .033 & & & .129 & .897 & & \\
\hline 4 & .128 & .016 & & & .064 & .961 & & \\
\hline 5 & .080 & .006 & & & .025 & .986 & & \\
\hline 6 & .049 & .002 & & & .009 & .995 & & \\
\hline 7 & .035 & .001 & & & .005 & 1.000 & & \\
\hline Total & & .256 & 467.745 & $<.001$ & 1.000 & 1.000 & & \\
\hline
\end{tabular}

The number (.256) in bottom of inertia column indicates that knowing something about visit purpose explains $25.6 \%$ of something shopping items and vice versa.

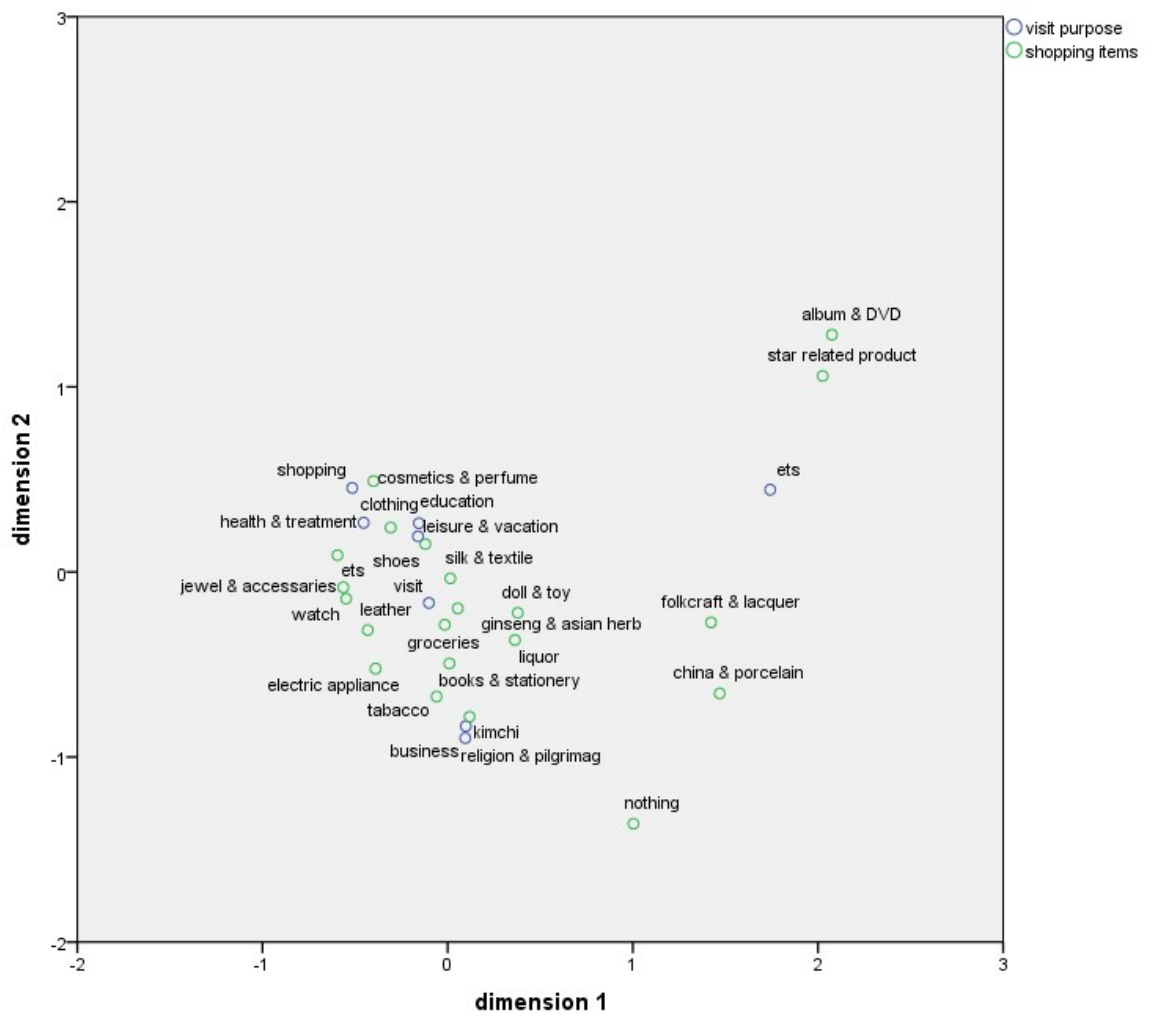

Figure 6: Row and column points with symmetric normalization

We can suggest that 'cosmetics \& perfume', 'clothing', 'shoes' among shopping items are, in particular, related to 'shopping', 'health treatment', and 'leisure \& vacation', respectively (see Figure 6). On the other hand, 'kimchi' is marginally concerned with both 'business' and 'religion \& pilgrimage' among visit purpose, while 'visit' is to both 'ginseng \& Asian herb' and 'groceries' among shopping items. 


\subsection{Association between other demographics and shopping items}

Now, we take into account associations with shopping items and other demographics - gender, age, occupation and month. 'Cosmetics \& perfume', 'clothing' and 'groceries' are on the whole main shopping items which foreign tourists for all demographics (see Figures 7-10).

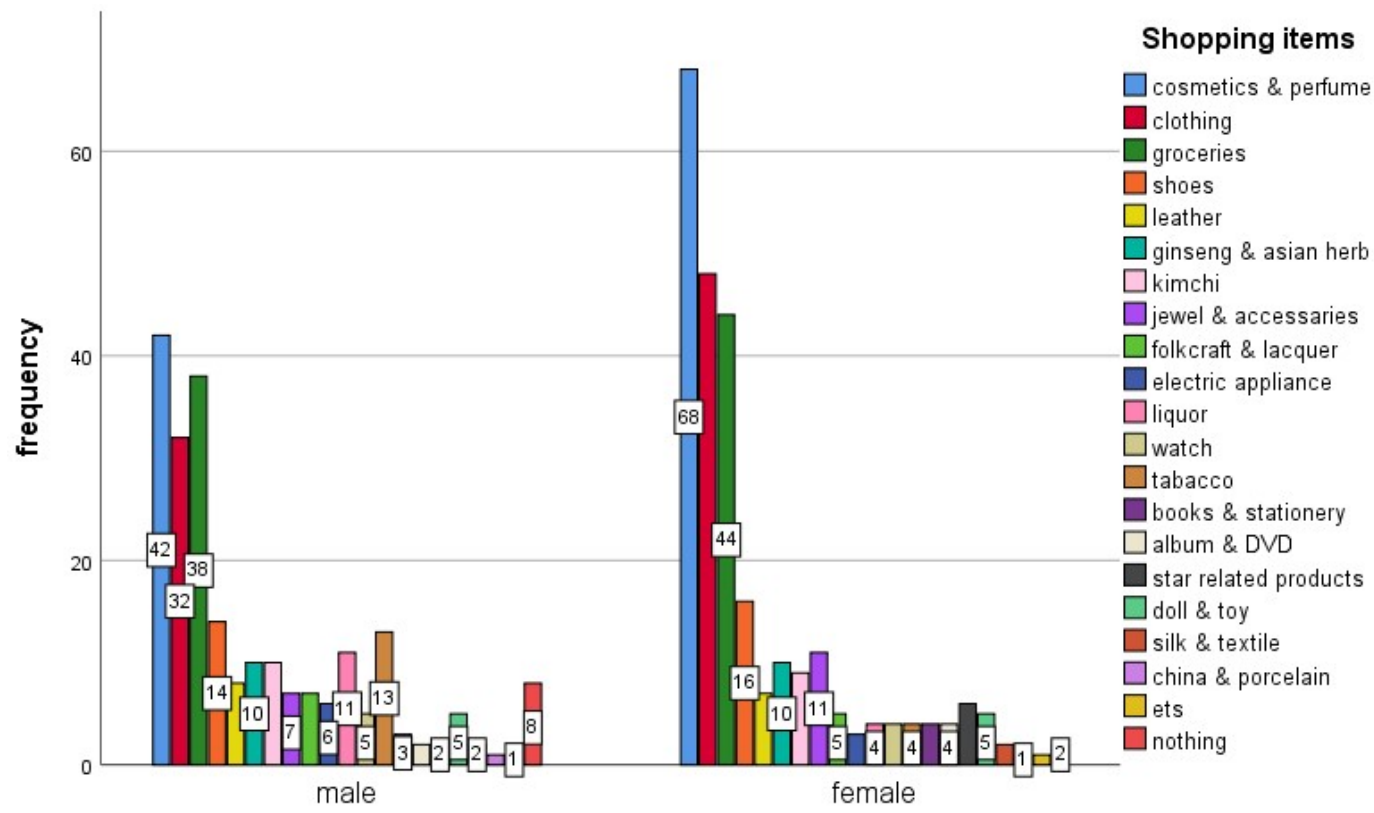

Figure 7: Bar chart on GENDER

We can find that there is no big difference between male and female by gender in terms of total expenditure. In particular, three popular items above - 'cosmetics \& perfume', 'clothing', and 'groceries' - account for $49.3 \%$ and $62.1 \%$ of male and female, respectively. As we can expect, 'liquor', and 'tabacco' are more preferred by male rather than by female $(4.8 \%$ and $5.7 \%$, respectively). 'Cosmetics \& perfumes' is most frequent item among 21 ones regardless of gender $(42,22.7 \%$ of total expenditure). In addition, we cannot find the distinct statistical association between gender and shopping items $(\mathrm{p}$-value $=.204)$.

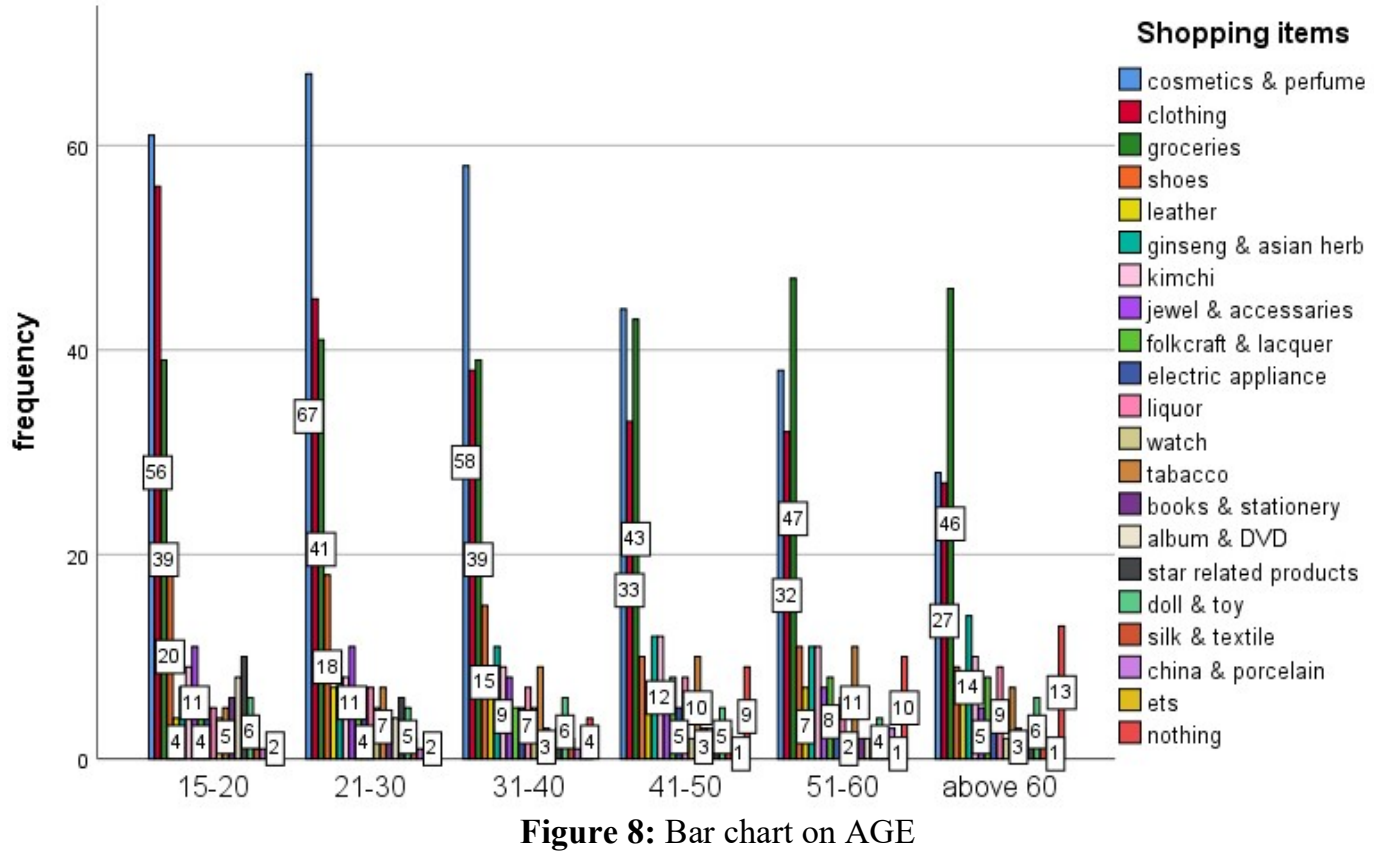


For all attributes of age and occupation, 'cosmetics \& perfume', 'clothing', and 'groceries' are the key factors to explain shopping items. In particular, (21-30, cosmetics \& perfume) and (student, cosmetics \& perfume) are the most frequent combination of age and occupation. For occupation, 'self-employed' is the largest (265) whereas 'businessman' is the smallest (213) in number. For age, (15-20) is the largest (264), while 'above 60' is the smallest in number (208).

Looking over two chi-squared tests suggest no significance, claiming two hypotheses that age and shopping items are associated with each other, and occupation and shopping items are associated with each other (pvalue $=.427$ and .727 , respectively).

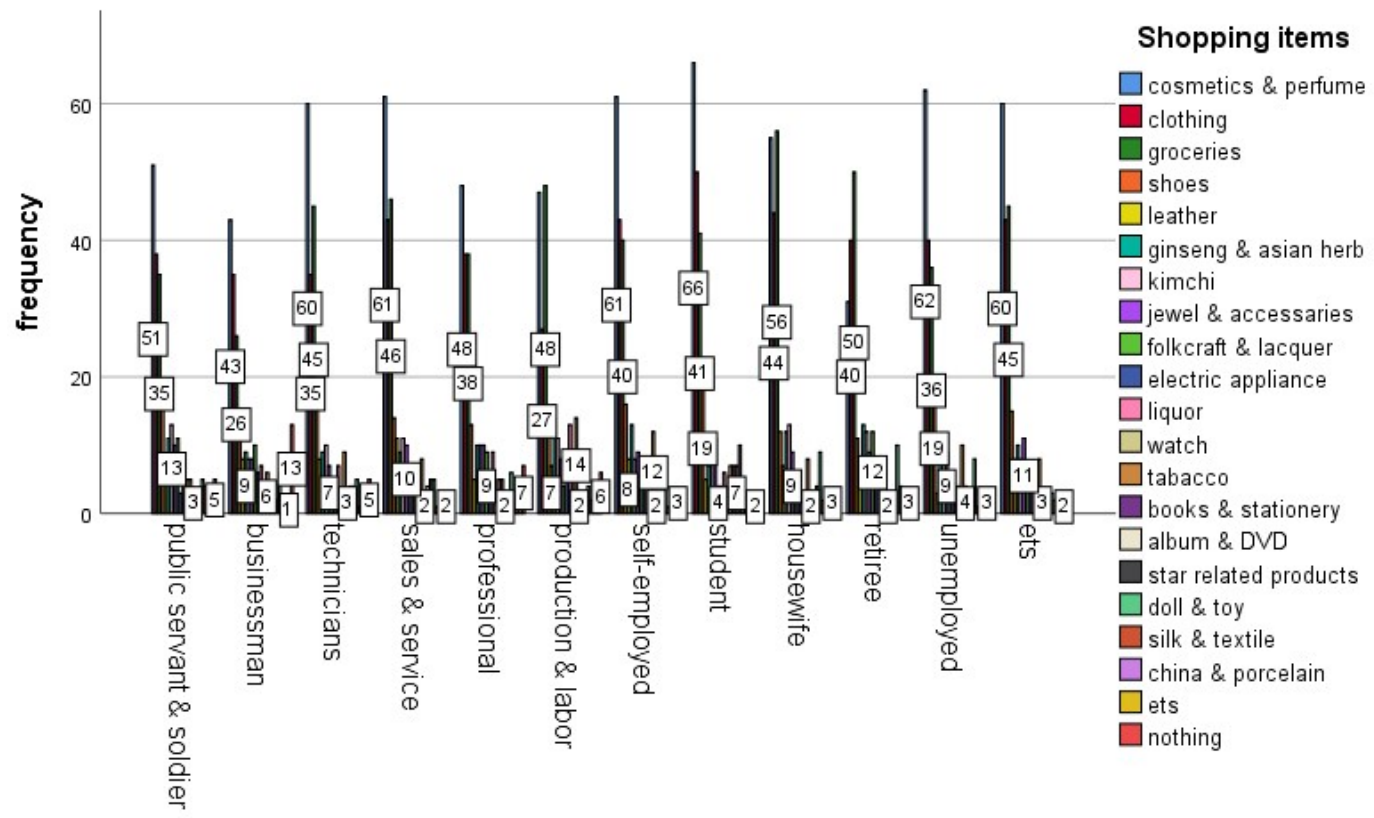

Figure 9: Bar chart on OCCUPATION

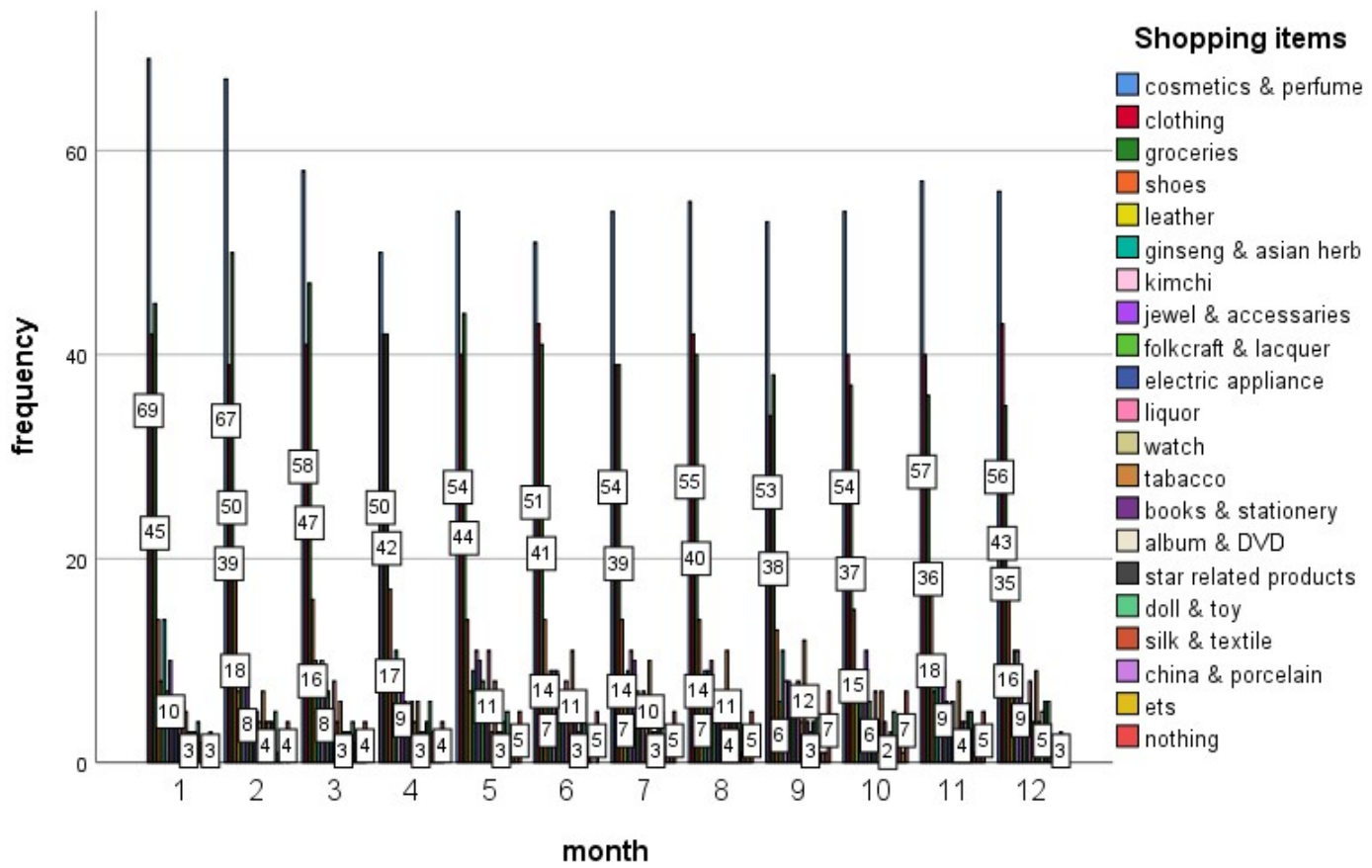

Figure 10: Bar chart on VISIT MONTH 
As you can see from Figure 10, total expenditure fluctuates around the fixed value each month, and 'cosmetics \& perfume' among shopping items is most preferred by foreign tourists every month. In addition, there is no statistical association between visit month and shopping items $(\mathrm{p}$-value $=.959)$.

\section{Concluding Remarks and Limitations}

In this work, we examine and evaluate the intimate associations between two qualitative variables, shopping items and the seven demographics by utilizing chi-squared test and correspondence analysis. In particular, correspondence analysis is the useful technique to make the association between several variables concrete and visual by changing to orthogonal components that optimize the segregation between column and row scores.

In summary, shopping items which foreign tourists purchase are closely associated with the three different demographics variables - country of residence, tour type and visit purpose by monitoring significant $p$-value of chisquared statistic.

The results obtained by correspondence analysis are the following: 'cosmetics \& perfume', 'clothing', and 'groceries' are the major shopping items among 21 attributes for all demographics variables in this research. In particular, 'groceries' has to do with a lot Japan (country of residence), air-tel tour (tour type), and visit (visit purpose), while 'kimchi' does 'China' and 'Philippines', 'business and religion \& pilgrimage' and 'group tour'.

In addition, 'clothing' closely connects with 'Malaysia', 'air-tel tour and health treatment. As a leading byproduct of findings, 'cosmetics \& perfume' intimately relates to 'shopping' among visit purpose.

Through this study, the trends and preferences of shopping goods purchased by foreigners visiting Korea can be, in detail, detected, so that a granular sales strategy will help to strengthen the country's tourism competitiveness. In this research, we consider only several demographics variables such as gender, age, occupations, country of residence, visit month, visit purpose and trip type in order to detect associations with shopping items, which foreign tourists purchase in South Korea.

Taking into account more segmented demographics, we can extend to administrative units such as small city or county, more specialized religion and schooling years of foreign tourists, business career of foreign tourists and so on in the future. Shopping behaviors of foreign tourists should be specialized on shopping tourism service quality, and both their traits and each cluster be identified. Therefore, we can materialize and classify foreign tourists on the service quality of a shopping tourism stressing on the inbound tourists (Kim et al, 2014).

Government authority in South Korea should carefully weigh up exploring organization of goods and services, and retail tactic and Korean retailers should contrive more elaborate packaging-service for Japanese tourists. For Chinese tourists, in particular, Korean retailers should explore ways to upgrade communication with Chinese tourists and ability to account for characteristic of products and services in Chinese. Ministry of Culture, Sports and Tourism in South Korea should improve appropriate programs to educate the retailers and tour conductors, so that they can better satisfaction of foreign tourists for the shopping properties in which they are unsatisfied (Park \& Jeong, 2010).

\section{References}

Benzercri, J. P. (1992). Correspondence analysis handbook. New York: Marcel Decker.

Brigitte, Le R. (2009). Multiple correspondence analysis. Thousand Oaks, CA: Sage Publications.

Clausen, S. E. (1988). Applied correspondence analysis: an introduction. Thousand Oaks, CA: Sage Publications.

Doey, L., \& Kurta, J. (2011). Correspondence analysis applied to psychological research. Tutorials in Quantitative Methods for Psychology, 7(1), 5-14.

Greenacre, M. J. (1984). Theory and applications of correspondence analysis. New York: Academic Press.

Greenacre, M. J. (2007). Correspondence analysis in practice. Boca Raton, Florida: Taylor and Francis Group.

Hair, J. F., Black, B., Babin, B., Anderson, R. E., \& Tatham, R. L. (2007). Multivariate data analysis. Toronto: Prentice Hall.

Hoffman, D. L., \& Franke, G. R. (1986). Correspondence analysis: graphical representation of categorical data in marketing research. Journal of Marketing Research, 23(3), 213-227.

Jeong, D. B. (2019). Evaluation of shopping items: focused on purchase of foreign tourists in South Korea. East Asian Journal of Business Economics, 7(2), 21-30 
Kim, E. P., Lee, H. S., \& Lee, M. H. (2014). A Research on the design preference based on the survey of purchasing cultural sightseeing souvenirs by foreign tourists - Based on the sales results of cultural sightseeing souvenirs in Insa-dong, Seoul. Korea Science \& Art Forum, 15(1), 103-114.

Nakahara, R. (2017). Interests between global consumer and local residence - relations and gaps between the foreign tourists and local residents. Global Fashion Management Conference, 7(1), 1-29.

Park, C. H., \& Jeong, W. S. (2010). A Comparison of Shopping Satisfaction of Japanese and Chinese Tourists in Korea. The Review of Eurasian Studies, 7(4), 35-51.

Steven, J. P. (2009). Applied multivariate statistics for the social sciences. New York: Lawrence Erlbaum Associates Inc.

Yang, B. H. (2013). Understanding multivariate analysis. Seoul, Korea: Communication books. 